\title{
Experimental and Numerical Investigation about Small Clearance Journal Bearings under Static Load Conditions
}

\author{
Carlo Alberto Niccolini Marmont Du Haut Champ $\mathbb{D D}^{1}{ }^{1}$ Fabrizio Stefani $\left(\mathbb{D},{ }^{2}\right.$ \\ and Paolo Silvestri $\mathbb{D D}^{1}$ \\ ${ }^{1}$ University of Genoa, DIME, Thermochemical Power Group (TPG), Genoa, Italy \\ ${ }^{2}$ University of Genoa, DIME, Genoa, Italy \\ Correspondence should be addressed to Carlo Alberto Niccolini Marmont Du Haut Champ; carlo.niccolini@edu.unige.it
}

Received 3 June 2020; Accepted 26 November 2020; Published 4 December 2020

Academic Editor: Jerzy T. Sawicki

Copyright (c) 2020 Carlo Alberto Niccolini Marmont Du Haut Champ et al. This is an open access article distributed under the Creative Commons Attribution License, which permits unrestricted use, distribution, and reproduction in any medium, provided the original work is properly cited.

\begin{abstract}
The aim of the present research is to characterize both experimentally and numerically journal bearings with low radial clearances for rotors in small-scale applications (e.g., microgas turbines); their diameter is in the order of ten millimetres, leading to very small dimensional clearances when the typical relative ones (order of 1/1000) are employed; investigating this particular class of journal bearings under static and dynamic loading conditions represents something unexplored. To this goal, a suitable test rig was designed and the performance of its bearings was investigated under steady load. For the sake of comparison, numerical simulations of the lubrication were also performed by means of a simplified model. The original test rig adopted is a commercial rotor kit (RK), but substantial modifications were carried out in order to allow significant measurements. Indeed, the relative radial clearance of RK4 RK bearings is about $2 / 100$, while it is around $1 / 1000$ in industrial bearings. Therefore, the same original RK bearings are employed in this new test rig, but a new shaft was designed to reduce their original clearance. The new custom shaft allows to study bearing behaviour for different clearances, since it is equipped with interchangeable journals. Experimental data obtained by this test rig are then compared with further results of more sophisticated simulations. They were carried out by means of an in-house developed finite element (FEM) code, suitable for thermoelasto-hydrodynamic (TEHD) analysis of journal bearings both in static and dynamic conditions. In this paper, bearing static performances are studied to assess the reliability of the experimental journal location predictions by comparing them with the ones coming from already validated numerical codes. Such comparisons are presented both for large and small clearance bearings of original and modified RKs, respectively. Good agreement is found only for the modified RK equipped with small clearance bearings (relative radial clearance 8/1000), as expected. In comparison with two-dimensional lubrication analysis, three-dimensional simulation improves prediction of journal location and correlation with experimental results.
\end{abstract}

\section{Introduction}

Hydrodynamic journal bearings and more, in general, fluid film bearings are often employed to support rotors in modern power plants (e.g., micro-GT fuel cell hybrid systems) and crankshafts in automotive applications (e.g., connecting rod bearing in internal combustion engines). Their working principle is based on the interposition of a thin self-pressurized lubricant film between the two opposing bearing surfaces that are in relative motion. For instance, assuming that the relative radial clearance is one per thousandth $(1 / 1000)$, since journal diameters of micro-
GT bearings are usually in the range $10-20 \mathrm{~mm}$, film thickness is about 10 microns [1]. Therefore, very highquality standards and tolerances are required to produce this class of bearings, which must be manufactured with high precision processes.

The comparison of experimental and numerical results has been employed in the first studies on instability of hydrodynamic journal bearings. For example, by considering all of the nonlinear terms in equations and using in-house developed test rigs, the effect of both journal and bearing defects on stability has been studied [2]. 
More recently, experimental investigations have focused on journal bearing friction. In [3], an innovative test rig has been employed in order to evaluate friction with high measurement accuracy. The authors have carried out different tests varying load and sliding velocity both in mixed and full film lubrication regimes. They have obtained results in the form of a Stribeck curve whose trend is in good agreement with literature findings.

The static and dynamic performances of small hydrodynamic journal bearings (i.e., in laboratory applications) have already been investigated in several works by means of both numerical methods and RK-type experimental test rigs. For instance, Tůma and Biloš [4] have studied the stability of rotor vibrations in a journal bearing by means of full spectrum analysis and a RK4 Rotor Kit device; they have concluded that journal motion inside the bearing is ruled by two equations of motion, which can be referred to as linear and nonlinear models. Meruane and Pascual [5] have found that nonlinear dynamic coefficients can strongly affect their stiffness and damping. They have employed a CFD simulation model in ADINA and a Rotor Kit 2000 experimental rig. Tůma et al. [6] have carried out both experimental and theoretical investigations to assess the influence of external excitations on rotor behaviour and stability: according to the obtained results, they have found out that kinematic excitation can affect amplitudes of vibration but not the stability limit. They have taken advantage of both a lumped parameter model for the numerical simulations and a RK4 RK together with a suitable test stand (bearing diameter $30 \mathrm{~mm}$ ) for the rotor active control experimental.

Deepak and Noah [7] have taken advantage of a commercial RK to study the effects of load, speed, and imbalance mass on the journal dynamic behaviour; they experimentally proved it can undergo instability with supercritical or subcritical bifurcation, according to Hopf bifurcation theory (HBT), varying shaft stiffness, imbalance mass, and the magnitude of external perturbations applied to the system. They made use of sleeve bearings in their investigation. The authors performed experimental investigations in order to assess the reliability of $\mathrm{HBT}$ in predicting instability behaviour of cylindrical fluid film bearings exploiting again a commercial RK. Van De Vorst et al. [8] performed numerical investigations on static behaviour of flexible rotordynamic systems supported by one hydrodynamic journal bearing, without comparing them to experimental results; indeed, it is difficult to find works in the literature in which a RK-type test bench has been used to perform static measurements with small clearances, like what it is meant to do in this work. All of the abovecited works do rely on experimental results obtained by means of large clearance journal bearings when compared to industrial ones, which relative radial clearance is in the order of one per thousandth (1/1000), as previously mentioned. Indeed, from our measurement, relative radial clearance of RK 4 original bearings is 1.7/100 at ambient temperature, as reported in the following, while also for Rotor Kit 2000, a high value of relative radial clearance $(1.3 / 100$ at ambient temperature) can be found in [5]. In addition, due to differential thermal dilatation, the hot relative radial clearance increases during operating conditions.

In all of the previous cited papers about dynamics, the ratio $c / R$ (relative radial clearance) is not similar to the one which is encountered in real bearings, but it is always very high and far from the values employed in industrial field. At this end, here we mean to fill this lack starting from static investigations. The aim of the presented research project is then to develop test benches and simulation methods wellsuited for the reliable assessment of performance and stability characteristics of small fluid film bearings designed with significant relative clearance values for rotors in different applications, with particular reference to their vibrational and rotordynamic behaviour. In this perspective, the comparison of numerical prediction and experimental measurement of journal locations inside the bearing is essential. Furthermore, the analysed test-rig bearings should work in significant operating conditions, characterized by small values of film thickness, i.e., hot relative clearance in the order of one per a thousandth (1/1000). To this goal, tested bearings should have much lower relative clearance in comparison with original RK supports and, at the same time, they should still allow the assembly of the modified test bench, together with ensuring a good alignment between the two supports of the shaft. Since the original RK is not designed with clearance values typical of actual industrial journal bearings, in order to preserve its original dimensions, it is mandatory to reach higher precision and tolerances levels. Enhanced manufacturing of the new test rig is a key aspect in the presented investigation. Indeed, in order to satisfy the abovecited requirements while maintaining negligible rotor assembly errors and acceptable geometrical defects, it is essential to employ high-precision mechanical manufacturing processes. At this beginning step of the research activity, the test-rig bearings have been lightly loaded. Indeed, manufacturing problems and structural resonance characteristics have limited the total mass of the shaft. Hence, in order to achieve realistic operating loads, springs or other additional loading components would have been required. Since the test rig is aimed to study dynamic phenomena and fluid-structure interactions after the present preliminary setup study, its structure has been kept as simple as possible. Nevertheless, it is already planned to modify the shaft design in order to increase its mass without introducing strong modification of its critical speeds.

The present work is aimed to setup the test rig for future dynamic analyses on small journal bearings with realistic relative clearance. To this goal, it is essential to study the static behaviour of the bearings in study and, particularly, to measure journal locations with the highest possible accuracy. In order to assess the reliability of measurements, they have been compared with numerical results coming from inhouse developed FEM codes already validated in the past $[9,10]$.

In conclusion, in the present paper, in order to obtain the best design and a basic setup of this modified test bench, the influence of bearing clearance in the assessment of the static journal equilibrium position in hydrodynamic journal 
bearings is investigated by comparing experimental and numerical results.

Numerical simulations have been performed by using a previously validated $[9,10]$ in-house developed FEM code for journal bearing TEHD analysis. Since the simulation models rely on the classical Reynolds hypothesis which assumes a thin lubricant film, bearing clearance must be enough small in the experiments in order to satisfy simplification of Navier-Stokes general momentum equations.

\section{Experimental Devices}

Rotordynamic investigations can be performed on simplified rotor models, arranged in order to reproduce particular working conditions of actual rotating machines. The first experiments were performed on the original RK. Subsequently, a modified version of the RK was designed for further measurements.

The first experimental device used for measurements is the RK4 Rotor Kit [11]. This original RK is a modular rotating machine, that can be assembled and operated in several arrangements. In the original configuration that is adopted in the experiments, the shaft is supported by a fluid film bearing on one side and by a self-lubricated bush located at its opposite end. RK4 RK is furnished with an electric motor, which allows regulation of rotation speed in modulus and direction in the range $250-10000 \mathrm{rpm}$, and it is equipped with a frame characterized by a V-shaped design which houses motor, bearings, and rotor. The fluid film bearing is expected to work in hydrodynamic lubrication regime under nominal supply pressure $(0.007 \mathrm{MPa})$ and, in order to be able to avoid possible inception of oil-whirl instability, it can add hydrostatic lift if it is fed at higher pressure (up to $0.24 \mathrm{MPa}$ ).

The bearing assembly is provided with holes that support proximity sensors. These magnetic probes can detect with high-accuracy journal displacements in two directions $(X$ and $Y$ ) normal to the rotor axis, which are turned into voltage variations. More in detail, they are eddy current proximity sensors that are capable of measuring displacements of any desired shaft point. They are connected to a special external unit (proximitor assembly), which can receive and acquire signals coming from five different channels simultaneously. All of the proximity probes are arranged in pairs at right angles (Figure 1); therefore, both horizontal $(X)$ and vertical $(Y)$ displacement vector components are properly measured, as required by comparisons with FEM numerical results.

An oil tank is required in order to store lubricant fluid circulating during the journal rotation. The lubricant oil used during the present experimental campaign is ISO VG 32. In order to avoid measurement disturbances due to vibrations of the model structure, RK4 RK is supported by a massive and large marble basement mounted on four antivibrating supports. The acquisition hardware and software used during the experimental campaigns are provided by Siemens, and they are, respectively, LMS Scadas III and LMS Test Lab.

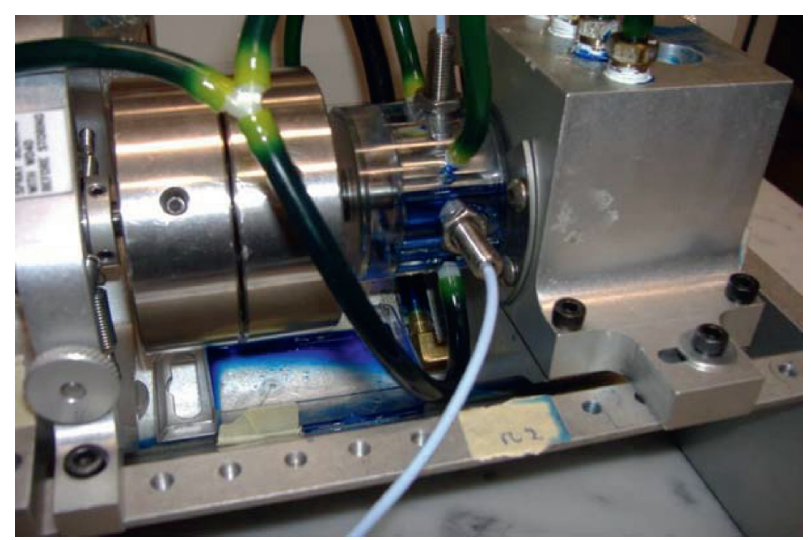

FIGURE 1: Instrumented hydrodynamic bearing with proximity probes.

RK4 original fluid film bearing is characterized by a too high-relative radial clearance (around one per hundredth), i.e., one order of magnitude more with respect to hydrodynamic journal bearings for industrial and automotive applications (which relative radial clearance is indeed about one per thousandth). Therefore, in order to increase the correlation between experiments and real-world applications, a new rotor with increased and variable journal diameter was designed. Such expedient allows us to reduce the fluid film bearing radial clearance without changing the bush. As a consequence, simulations by means of thin film assumption are expected to provide better agreement with experimental results. The new shaft designed for this modified RK can be equipped with variable diameter journals: this ensures a wide range of possibilities to study the hydrodynamic behaviour of the lubricant film. Indeed, relative radial clearance becomes now a variable parameter of the experiment. The journal instrumented with proximity sensors can be easily assembled by means of a splined connection. Figures 2 and 3 show assembly drawings of the new rotor designed for the modified RK and an actual image of the detail of the interchangeable journal, respectively.

The design of the new custom shaft has required proper dimensional and geometrical tolerances. Particularly, a total runout tolerance ensures shaft balancing and rectilinearity. In addition, in order to obtain the required radial clearance, suitable dimensional tolerances have been imposed to the journal diameter. For the results presented in this paper relevant to a relative hot radial clearance equal to $8 / 1000$, the dimensional tolerances of bearing and journal diameters are listed in Table 1, where modified RK geometrical data are reported, together with original RK ones for comparison. Since the journal and the bearing are, respectively, made of steel and polycarbonate (PC), the strong thermal differential dilatation has been taken into account in the choice of the dimensional tolerances applied to the journal diameter by assuming a working temperature of $40^{\circ} \mathrm{C}$ and linear radial dilatation of bush and shaft. Their differential variation is shown in Figure 4 as a function of temperature. Later, the computed hot clearance has been verified experimentally and good agreement has been found. Particularly, the 


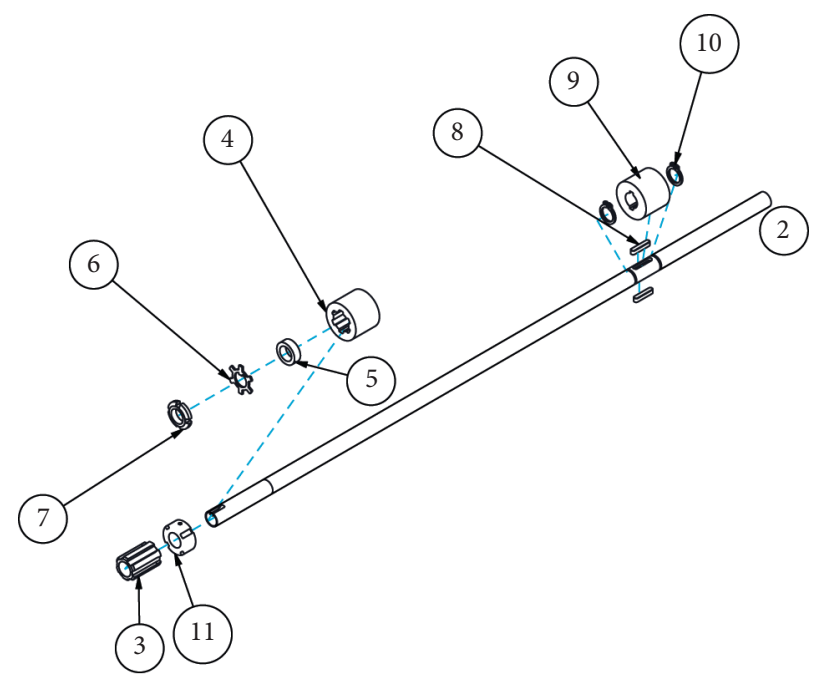

(a)
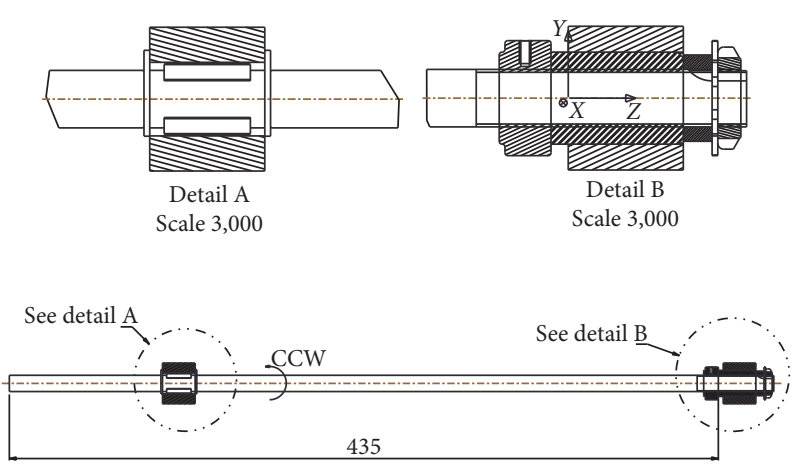

(b)

FIGURE 2: Shaft designed for the modified RK: (a) exploded view and (b) section. The following components are shown: (2) shaft; (3) splined connection; (4) splined hub (journal 1); (5) spacer; (6) safety washer; (7) threaded locking nut; (8) key; (9) hub with keyways (journal 2); (10) retaining ring; (11) lock nut with locking screw.

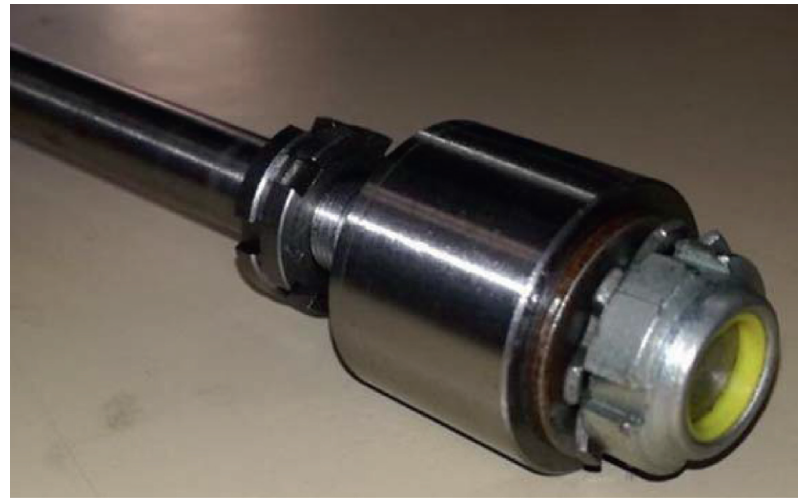

Figure 3: Prototype of the custom shaft with interchangeable journals.

experimental radial hot clearance is $109.5 \mu \mathrm{m}$, while the computed radial clearance at $40^{\circ} \mathrm{C}$ is $108 \mu \mathrm{m}$.

Experiments have been then carried out by taking advantage of this modified test rig in two different arrangements. The first configuration adopted (configuration 1), somehow inherited from the original RK, places the two shaft supports at opposite ends of the shaft, i.e., the hydrodynamic bearing to be investigated at the free shaft end and a selflubricated bush at the electric motor side (Figure 5). Differently, the second configuration (configuration 2) arranges another identical hydrodynamic bearing at the electric motor side (Figure 6); this second arrangement has been adopted in order to limit expected journal liftoff within the self-lubricated bearing. In any case, the oil supply pressure and temperature have been always controlled, respectively, in order to avoid hydrostatic lubrication conditions and to maintain temperature as constant as possible during tests. Indeed, the purpose of the present work is to test the bearings in hydrodynamic regime solely. Processing experimental data of configuration 1
TABLE 1: -Original-modified RK design data.

\begin{tabular}{|c|c|c|}
\hline Parameter (unit) & Symbol & $\begin{array}{c}\text { Value } \\
\text { (modified) }\end{array}$ \\
\hline Bearing length (mm) & $L$ & 20 \\
\hline Journal diameter $(\mathrm{mm})$ & $D$ & $25.245-25.254$ \\
\hline External diameter of bush (mm) & $D_{e}$ & 51 \\
\hline Inner diameter of bush (mm) & $D_{i}$ & 25.42 \\
\hline $\begin{array}{l}\text { Radial clearance (original RK) } \\
\text { (micron) }\end{array}$ & $c$ & 210 \\
\hline $\begin{array}{l}\text { Hot radial clearance (original RK) } \\
\text { (micron) }\end{array}$ & $c_{h}$ & 260 \\
\hline Relative radial clearance (original RK) & $c / R$ & $1.68 / 100$ \\
\hline $\begin{array}{l}\text { Radial clearance (modified RK) } \\
\text { (micron) }\end{array}$ & C & 90 \\
\hline $\begin{array}{l}\text { Hot radial clearance (modified RK) } \\
\text { (micron) }\end{array}$ & $c_{h}$ & 108 \\
\hline $\begin{array}{l}\text { Relative (hot) radial clearance } \\
\text { (modified RK) }\end{array}$ & $c_{h} / R$ & $8 / 1000$ \\
\hline Diameter of feed holes $(\mathrm{mm})$ & $d_{g}$ & 3.3 \\
\hline
\end{tabular}

have shown that such arrangement causes a certain climbing of the shaft due to the mixed lubrication conditions in the motor-side bearing, as described in [12]. Figures 7(a) and 7(b) plot two examples of time-averaged journal center orbits measured in configuration 1 and 2, respectively. As shown by the comparison of these figures, the orbits in configuration 1 are more likely to display angular points and locations with attitude angle higher than 90 degs.

\section{Numerical Models}

The experimental data are compared in the successive paragraphs with numerical results obtained by means of different simulation models, which are listed in Table 2, from the simplest to most complex. All of the models allow the 


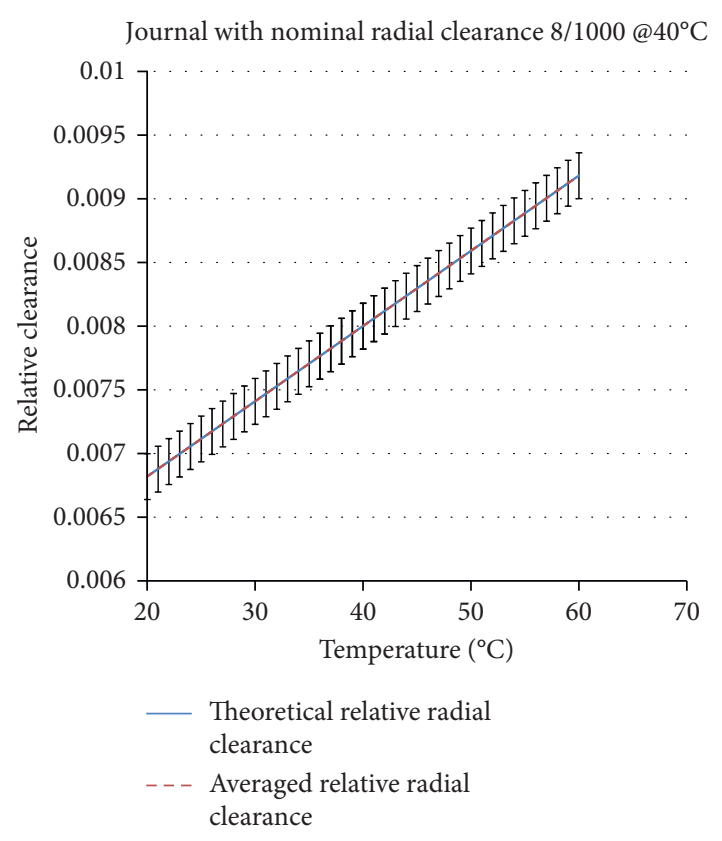

FIgURE 4: Relative radial clearance as a function of temperature.

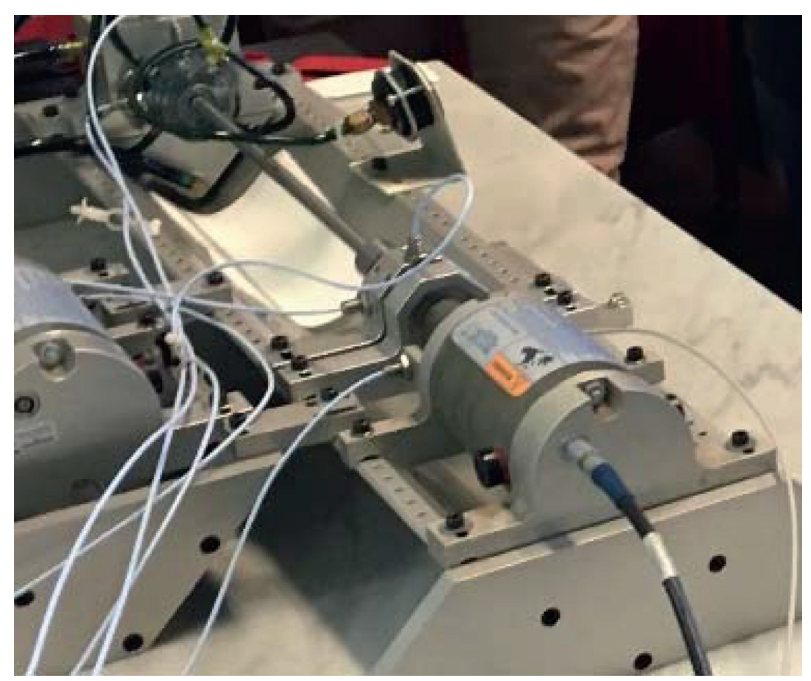

Figure 5: Rotor assembly mounted with custom shaft in configuration 1.

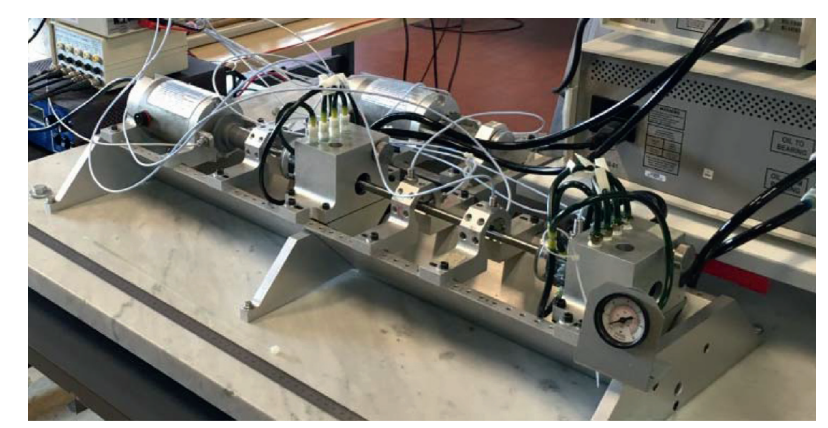

FIGURE 6: Rotor assembly mounted with custom shaft in configuration 2 . simulation of the fluid flow in the thin oil film (hydrodynamic submodel) as well as of heat generation and exchange in the lubricant (thermal submodel). In addition, the global model may include the simulation of heat conduction in the bush and journal (3D thermal submodel) and of thermomechanical deformation of the kinematic pair members (structural submodel). The three submodels can be coupled and solved simultaneously by using a suitable solution algorithm [9].

All of the models that require the solution of integrodifferential problems use the finite element method (FEM) for the discretization. Isoparametric 4-node rectangular and 8-node hexahedral elements for two-dimensional (2D) and three-dimensional (3D) problems are used.

All of the simulation models take advantage of mass conserving hydrodynamic submodels. They are based on the JFO theory $[13,14]$, which is valid for moderately and highly loaded bearings and assumes a cavitated film region with infinite streamers and variable density $\rho$. According to JFO theory, thin film mechanics equation for journal bearings is

$$
\begin{aligned}
\frac{\rho_{L}}{R^{2}} & \frac{\partial}{\partial \vartheta}\left(g_{L} \frac{\partial p}{\partial \vartheta}\right)+\rho_{L} \frac{\partial}{\partial z}\left(g_{L} \frac{\partial p}{\partial z}\right)-\omega \frac{\partial}{\partial \vartheta}\left[\rho\left(H-f_{L}\right)\right] \\
-\frac{\partial}{\partial t}(\rho H)=0 &
\end{aligned}
$$

where $p$ is the hydrodynamic pressure, $R$ is the journal radius, $\rho$ is the fluid film density, $\rho_{L}$ is the liquid phase density, $H$ is the film thickness, $\vartheta$ is the circumferential coordinate, $z$ is the axial coordinate, and $t$ is the time, while the remaining parameters are given by

$$
\left.\begin{array}{l}
f_{L}=\frac{i_{L 1}}{i_{L 0}} \\
g_{L}=\frac{i_{L 2}-i_{L 1}^{2}}{i_{L 0}}
\end{array}\right\},
$$

where $\mu_{L}$ is the liquid dynamic viscosity and $y$ the cross-film coordinate.

Equation (1) rules the lubricant flow in the " $3 \mathrm{D}$ mass conserving" submodel. Indeed, although lubrication problem is two-dimensional (in $\vartheta, z$ coordinate domain), it considers the cross-film variation of viscosity. Hence, the $3 \mathrm{D}$ mass conserving submodel is used together with $3 \mathrm{D}$ thermal models.

Differently, the 2D mass conserving submodel complies with the following form of thin film mechanics equation:

$$
\begin{aligned}
\frac{\rho_{L}}{R^{2}} & \frac{\partial}{\partial \vartheta}\left(\frac{H^{3}}{12 \mu_{L}} \frac{\partial p}{\partial \vartheta}\right)+\rho_{L} \frac{\partial}{\partial z}\left(\frac{H^{3}}{12 \mu_{L}} \frac{\partial p}{\partial z}\right)-\frac{\omega}{2} \frac{\partial}{\partial \vartheta}(\rho H) \\
- & \frac{\partial}{\partial t}(\rho H)=0,
\end{aligned}
$$

which is a particularization of equation (1) for constant $\mu_{L}$ and resembles the classic Reynolds equation. Equations (1) and (3) are solved in weak form in agreement with [1]. 


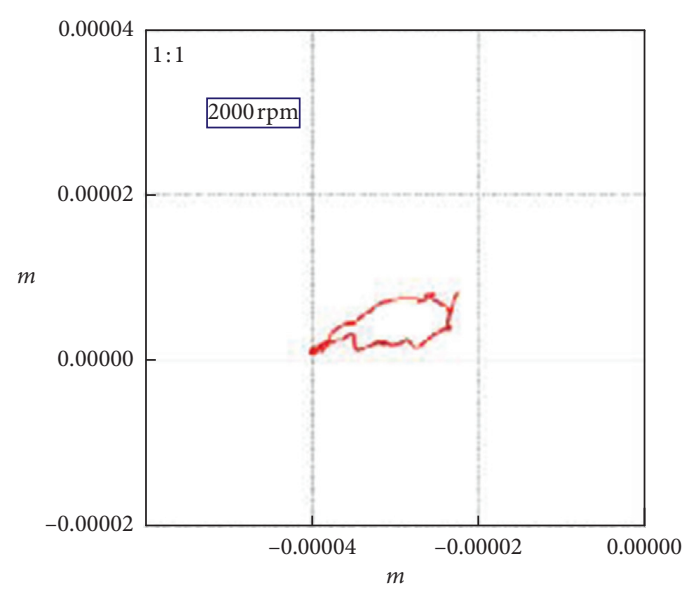

(a)

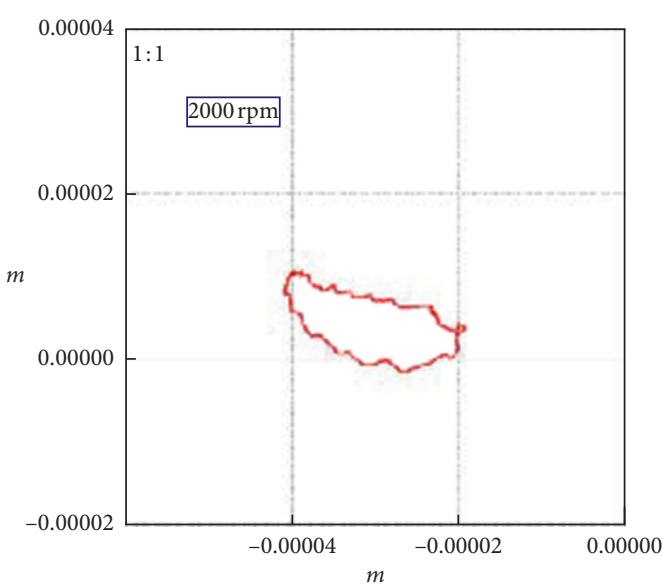

(b)

Figure 7: Averaged orbit at $250 \mathrm{rpm}$ : (a) configuration 1, (b) configuration 2.

TABLE 2: Simulation models and submodels.

\begin{tabular}{|c|c|c|c|c|c|}
\hline Model name & $\begin{array}{l}\text { Analysis } \\
\text { type }\end{array}$ & $\begin{array}{l}\text { Hydrodynamic } \\
\text { submodel }\end{array}$ & Thermal submodel & Structural submodel & Variants \\
\hline THD 2D adiabatic & THD & 2D mass conserving & 2D adiabatic & - & - \\
\hline THD 2D correlation & THD & 2D mass conserving & $\begin{array}{l}\text { 2D with Luke } \\
\text { formula }\end{array}$ & - & - \\
\hline THD 3D & THD & $3 \mathrm{D}$ mass conserving & 3D conduction & - & - \\
\hline TEHD 3D (free expansion) & TEHD & 3D mass conserving & 3D conduction & $\begin{array}{l}3 \mathrm{D} \\
\text { thermomechanical }\end{array}$ & Free expansion \\
\hline $\begin{array}{l}\text { TEHD 3D (radial } \\
\text { constraint) }\end{array}$ & TEHD & $3 \mathrm{D}$ mass conserving & 3D conduction & $\begin{array}{l}3 \mathrm{D} \\
\text { thermomechanical }\end{array}$ & $\begin{array}{l}\text { Partial radial } \\
\text { constraint }\end{array}$ \\
\hline
\end{tabular}

As far as the film domain is concerned, the thermal submodel relies on the cross-film averaged energy equation:

$$
\frac{\partial}{R^{2} \partial \vartheta}\left(k H \frac{\partial T_{m}}{\partial \vartheta}\right)+\frac{\partial}{\partial z}\left(k H \frac{\partial T_{m}}{\partial z}\right)-\rho c H\left(u_{m} \frac{\partial T_{m}}{R \partial \vartheta}+w_{m} \frac{\partial T_{m}}{\partial z}\right)-\rho c H \frac{\partial T_{m}}{\partial t}+H \Phi_{m}-q_{0}-q_{1}=0
$$

where $u$ and $w$ are the circumferential and axial fluid velocities, respectively, $k$ is the conductivity of the film, $c$ is the specific heat, $T$ is the film temperature, $\Phi$ is the power dissipation density function, and the subscript $m$ denotes a variable averaged in the cross-film direction.

In addition, $q_{0}$ and $q_{1}$ are the heat transfers (per unit area) to bearing and journal surfaces, respectively. If they are both equal to zero, the thermal submodel is referred to as " $2 \mathrm{D}$ adiabatic" [15], although heat exchange is allowed in the feed grooves [1]. By using Luke formula [16], $q_{0}$ and $q_{1}$ can be computed [17] and the heat exchange can be roughly taken into account ("2D with Luke formula" submodel). To this goal, in THD 2D correlation model bush and journal temperature are assumed to be constant and equal to the corresponding averaged temperatures, TB and TS, respectively, reported in Table 3. In the " $3 \mathrm{D}$ conduction" submodel, $q_{0}$ and $q_{1}$ are calculated by obtaining the temperature gradients at the walls, in the hypothesis that the temperature profile across the film thickness is a fourthorder polynomial [9]. Only this last thermal submodel requires FEM simulation of heat conduction in both bush and journal, while the same finite element mesh of the bush, shown in Figure 8, is used to simulate structural deformations ("3D thermomechanical" submodel) due to pressure and temperature rise [10]. Two variants of such submodel are arranged with different boundary conditions. In the first variant ("free expansion"), the thermomechanical model of the polycarbonate bearing is left free to expand radially over its entire outer surface. In the second ("partial radial constraint"), the part of the bearing inserted in the frame (delimited by the two O-ring grooves) is radially constrained. In reality, the radial expansion of the bearing in 
TABLE 3: Lubrication analysis data.

\begin{tabular}{|c|c|c|}
\hline Parameter (unit) & Symbol & Value \\
\hline $\begin{array}{l}\text { Viscosity }\left(\text { at } T_{0}=40^{\circ} \mathrm{C}\right)(\mathrm{Pa} \mathrm{s}) \\
\text { Viscosity temperature coefficient }\left(1 /{ }^{\circ} \mathrm{C}\right) \\
\text { Mass density }\left(\mathrm{kg} / \mathrm{m}^{3}\right) \\
\text { Specific heat }\left(\mathrm{J} / \mathrm{kg}^{\circ} \mathrm{C}\right) \\
\text { Thermal conductivity }(\mathrm{Wm} / \mathrm{K})\end{array}$ & $\begin{array}{c}\mu_{L 0} \\
\beta \\
\rho_{L} \\
c_{L} \\
k_{L} \\
\end{array}$ & $\begin{array}{c}0.0251 \\
0.0317 \\
870 \\
2000 \\
0.14 \\
\end{array}$ \\
\hline \multicolumn{3}{|c|}{ Lubricant (ISO VG 32) properties } \\
\hline $\begin{array}{l}\text { Feed temperature }\left({ }^{\circ} \mathrm{C}\right) \\
\text { Feed pressure }(\mathrm{MPa})\end{array}$ & $\begin{array}{l}T_{s} \\
p_{s}\end{array}$ & $\begin{array}{c}51 \\
0.069\end{array}$ \\
\hline \multicolumn{3}{|l|}{ Supply conditions } \\
\hline $\begin{array}{l}\text { Bearing load (half shaft weight) for original } \\
\text { RK }(N)\end{array}$ & $W_{g}$ & 2.8 \\
\hline $\begin{array}{l}\text { Bearing load (half shaft weight) for modified } \\
\text { RK }(N)\end{array}$ & $W_{g}$ & 2.14 \\
\hline Environmental temperature $\left({ }^{\circ} \mathrm{C}\right)$ & $T_{e}$ & 20 \\
\hline Rotation speed range (rpm) & $\omega$ & $250-300$ \\
\hline \multicolumn{3}{|l|}{ Working conditions } \\
\hline Aver & $1_{B}$ & 51 \\
\hline Averaged journal tempera & $T_{S}$ & 40 \\
\hline Thermal conductivity of the bush $\left(\mathrm{W} /\left(\mathrm{m}^{\circ} \mathrm{C}\right)\right)$ & $k$ & 0.2 \\
\hline $\begin{array}{l}\text { Thermal conductivity of the journal }(\mathrm{W} / \\
\left.\left(\mathrm{m}^{\circ} \mathrm{C}\right)\right)\end{array}$ & $k_{j}$ & 50 \\
\hline Heat transfer coefficient $\left(\mathrm{W} /\left(\mathrm{m}^{2 \circ} \mathrm{C}\right)\right)$ & $h$ & 2 \\
\hline Young modulus (GPa) & $E$ & 2 \\
\hline Poisson ratio & $v$ & 0.37 \\
\hline $\begin{array}{l}\text { Linear dilatation coefficient }\left(1 /{ }^{\circ} \mathrm{C}\right) \\
\text { Thermomechanical data }\end{array}$ & $a$ & $710^{-5}$ \\
\hline
\end{tabular}

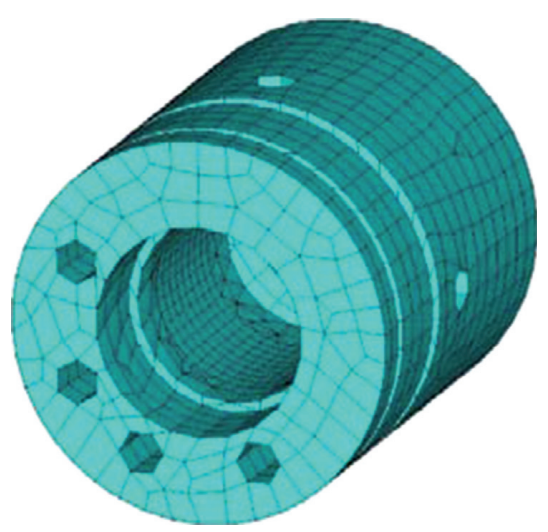

Figure 8: Bush model and mesh.

the insertion area will certainly be in an intermediate situation between the two simulated variants due to the differential dilatation. In all cases, in order to compute structural deformations due to pressure, "partial radial constraint" conditions are used. All of the data required for thermomechanical computations are included in Table 3.

As far as thermal boundary conditions applied to all of the $3 \mathrm{D}$ models are concerned, free convection is assumed at the external bushing surfaces. Differently, isothermal conditions are imposed on other surfaces inside the bushing, i.e., the bottom surface of the small reservoir for the leak oil as well as the bottom half of the four ducts that convey such lubricant to the external reservoir tank in the main frame. Table 3 lists all of the data relevant to 3D thermal boundary conditions. Particularly, for convection boundaries, it reports the overall heat transfer coefficient $h$ and the environmental temperature $T_{e}$ assumed as bulk temperature. In addition, the oil supply temperature $T_{s}$ is considered as the constrained temperature of the isothermal surfaces.

In $3 \mathrm{D}$ models, thermal simulation of the journal is carried out by means of uniaxial conduction elements, which model only the part of the steel shaft inside the bearing. At both the journal ends (first and last nodes of the mesh), isothermal conditions are assumed by imposing the averaged shaft temperature $T_{S}$. Its value is listed in Table 3 , together with the journal thermal conductivity $k_{j}$.

\section{Results}

Static characteristics have been computed by means of all of the global models listed in Table 2 and for the modified RK, while only $2 \mathrm{D}$ models have been used for the original RK, due to the large disagreement with experimental results, which does not mainly depend on the thermal model. The same bearing bushes have been employed in both original and modified RKs, while journal diameters are different, so that radial relative clearances are $1.68 / 100$ and $8 / 1000$, respectively. Lubricant supply is carried out by means of four holes in the bearing axial midplane oriented at 45 degs with reference to the vertical direction. Bearing data required by all of the lubrication analysis methods employed are listed in Tables 1 and 3. Hot clearances $c_{h}$ are used as input data for THD calculations. Here, the temperature-viscosity dependence is described by means of three parameters (reference oil viscosity $\mu_{L 0}$ at temperature $T_{0}$ and coefficient $\beta$ ) according to the exponential law described in [7]. The oil film in half bearing is discretized by means of $80 \times 8$ elements in circumferential and axial directions, respectively.

Experimental and numerical journal center locations (components $X, Y$ ) are shown in Figures 9-11 for the original and modified RKs in configuration 1 and 2, respectively. Journal locations are plotted at different shaft angular speeds $(250,500,1000,2000$, and $3000 \mathrm{rpm})$. Let $\varepsilon$ be the operational relative eccentricity equal to $e / c_{h}$, where $e=\left(X^{2}+Y^{2}\right)^{0.5}$. Black and red circles identify the loci of points located at $\varepsilon$ equal to 1 and 0.5 , respectively. The curves of different colors reported are useful to attribute the different computed positions to the relative method adopted to evaluate them. The reference system for position components $\left(e_{x}, e_{y}\right)$ has its origin in the bearing center; consequently, the represented position becomes the journal eccentricity expressed in dimensional terms. To allow a better comparison between experimental and numerical results, Figures 9-11 do not show the whole journal mobility area, which has a diameter of $0.2 \mathrm{~mm}\left(e_{x}\right.$ and $e_{y}$ values included between -0.1 and $0.1 \mathrm{~mm})$, but only a restricted area with half the diameter $\left(e_{x}\right.$ and $e_{y}$ values included between -0.05 and $0.05 \mathrm{~mm}$ ). Numerical data reported in Figures 9-11 are the same, and the three plots compare them with experimental results of the corresponding configuration adopted.

Experimental "static" journal points are obtained by averaging the measured locations during several shaft 


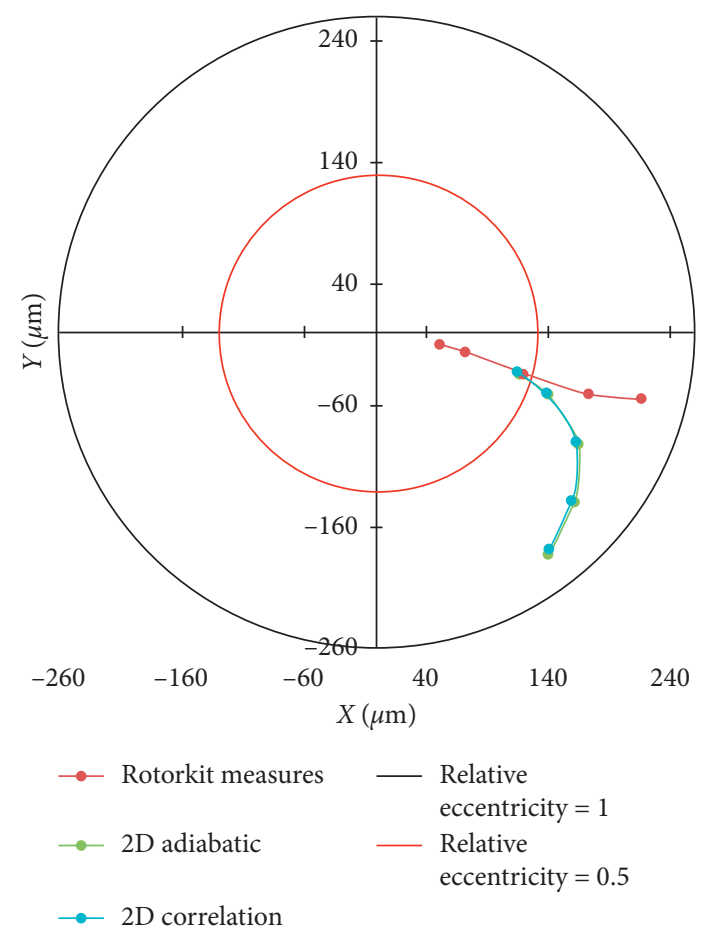

FIgURE 9: Journal center locations for the original RK.

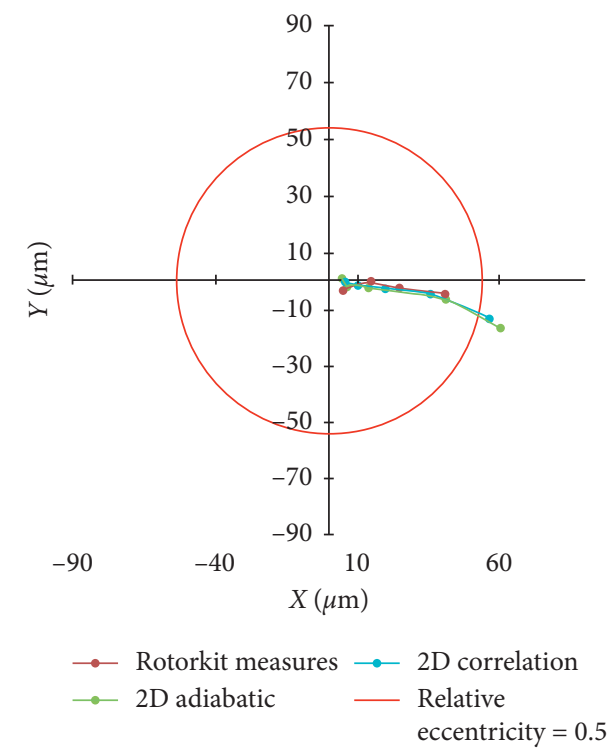

FIgURE 10: Journal center locations for the modified RK in configuration 1 .

rotations. Indeed, if the journal bearing works in steady conditions, the theoretical journal location does not vary with time, while its actual location undergoes small oscillations due to shaft unbalance and dynamics (in physical reality, a perfectly steady condition does not exist). Therefore, in actual "steady" conditions, the mean of the locations measured during several shaft rotation is required to identify the real journal location.

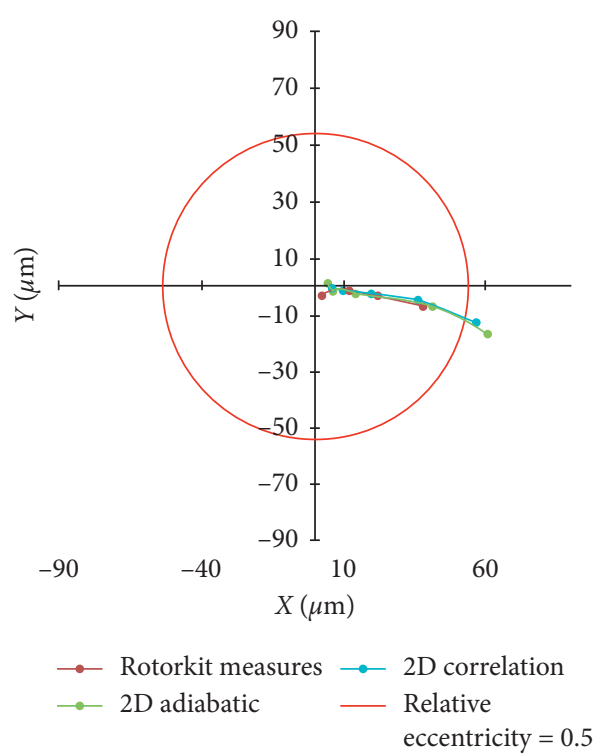

FIGURE 11: Journal center locations for the modified RK in configuration 2 .

Both in numerical and experimental cases, the obtained results exhibit a coherent trend of the journal position as the angular speed changes. By increasing rotational speed, the journal raises and moves itself towards bearing center in a continuous way (this trend permits an immediate identification of the rotational speed level for each operating condition reported in the plots).

The agreement between experimental analysis and all of the numerical simulations, which are based on thin film assumption, is better in the modified RK, both in configuration 1 and in configuration 2, than in the original RK, due to the clearance reduction. In experimental results relevant to configuration 1 of the modified RK the abovecited liftoff of the journal in the self-lubricated bearing may be influential and, together with misalignment, can explain the occurrence of positive $Y$ components of journal location. Indeed, the effects of misalignment can be considerable when rotational speed is not high and, particularly, for low external loads, as in the present experimental campaign. Such result has been proved and widely discussed in [18], where many tests are presented on hydrodynamic plain journal bearings submitted to misalignment torque controllable by means of a suitable experimental rig.

In order to assess the degree of agreement between experiments and simulations, Figures 12 and 13 plot in percentage the differences, also referred to as errors, between measured and relative eccentricities (the ratio between journal eccentricity and hot radial clearance) computed by means of two-dimensional (2D) THD models. Errors of "2D adiabatic" and " $2 \mathrm{D}$ correlation" models are reported in Figures 12 and 13, respectively. Modified RK errors both in configuration 1 and in configuration 2 (red and green columns, respectively) are far lower than original RK ones (blue columns). Thus, for further investigations and comparisons with numerical results from more advanced 
simulations, experimental results coming from the modified $\mathrm{RK}$ will be regarded as a reference.

Afterwards, full 3D simulations with THD and TEHD models have been carried out. The relevant results are then compared with measurements coming from both configurations of the modified RK.

Figures 14 and 15 report such comparison in terms of mobility plot for configurations 1 and 2, respectively. The model which is in best agreement with modified RK experimental data in both configurations is the "TEHD 3D radial constraint."

In the following, with the aim of a better visualization of computed and measured journal locations, numerical and experimental results are also compared in terms of polar coordinates, i.e., eccentricity ratio and attitude angle. Figures 16 and 17 plot relative eccentricity as a function of the rotor angular speed. For both the two configurations, the model which is in best agreement with experimental results is the "TEHD 3D radial constraint." More generally, all of the 3D models are in better agreement with the experimental reference results. Particularly, TEHD analysis still improves predictions in comparison with THD simulation.

With the same goal, Figures 18 and 19 compare attitude angle obtained numerically and experimentally in polar coordinates for the different rotational speeds. The closest numerical predictions for both the configurations come from the THD models ("THD 2D correlation" and "THD 3D"). Indeed, as far as attitude angles are concerned, they are in better agreement with modified RK measurements than the TEHD models (both "free expansion" and "radial constraint"). For both configurations of the modified RK, radial clearance values are very small; therefore, the measurement error in journal position may affect experimental evaluation of attitude angle when the journal moves close to the center of mobility area. The indeterminacy of the attitude angle near to the mobility region center yields high sensitivity of such parameter with respect to journal location.

As a consequence, such effect reduces the correlation between experimental and numerical results at the highest angular speed, when the journal runs almost centered. For the highest angular speeds, the error increase reveals measurement errors more significant than simulation ones. This issue has been encountered regardless of the considered numerical models, and this seems to further indicate a limit in the experimental data set.

The comparison between numerical and experimental curves points out that more sophisticated models are in better agreement with experimental results. Among twodimensional models, "THD 2D correlation" gives a slightly better agreement than "THD 2D adiabatic" and this improvement is more perceivable for low rotational speeds. In comparison, 3D models give predictions which are in better agreement with measurements, by means of the more accurate heat exchange simulation. Predictive differences among the 3D models are not remarkable. Indeed, although only the "TEHD 3D" model computes structural and thermomechanical deformations, the "THD 3D" model does not neglect thermal expansion, since it is included in the hot clearance value $(0.1 \mathrm{~mm})$ used as input for this model.

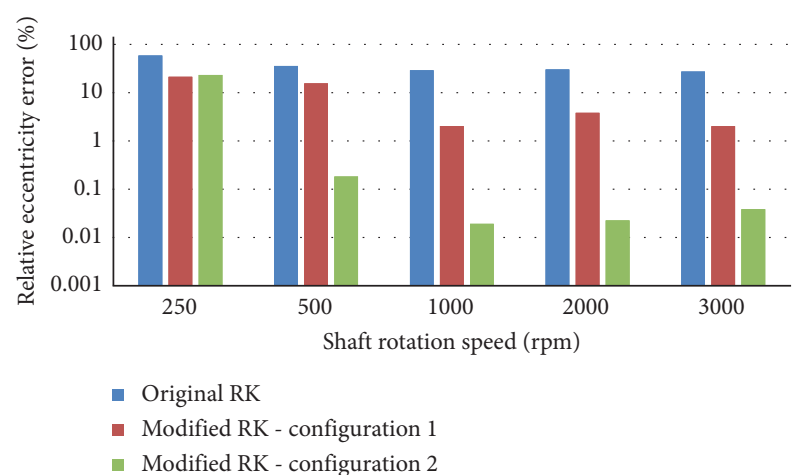

Figure 12: Difference between measured and 2D adiabatic model relative eccentricities for different test rigs (logarithmic scale).

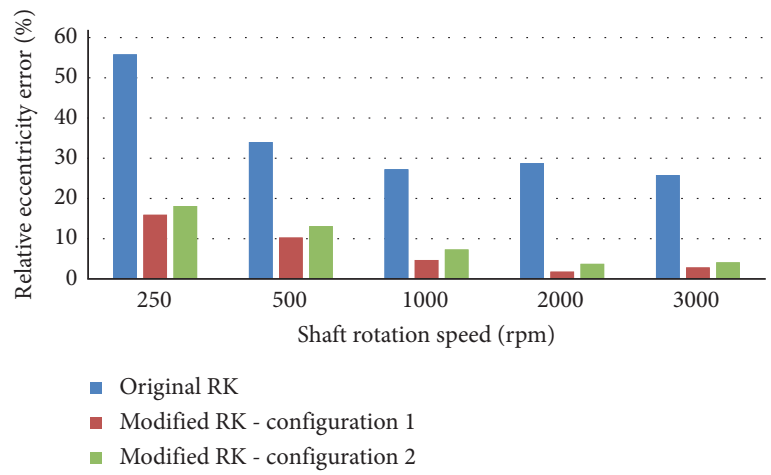

FIGURE 13: Difference between measured and 2D correlation model relative eccentricities for different test rigs.

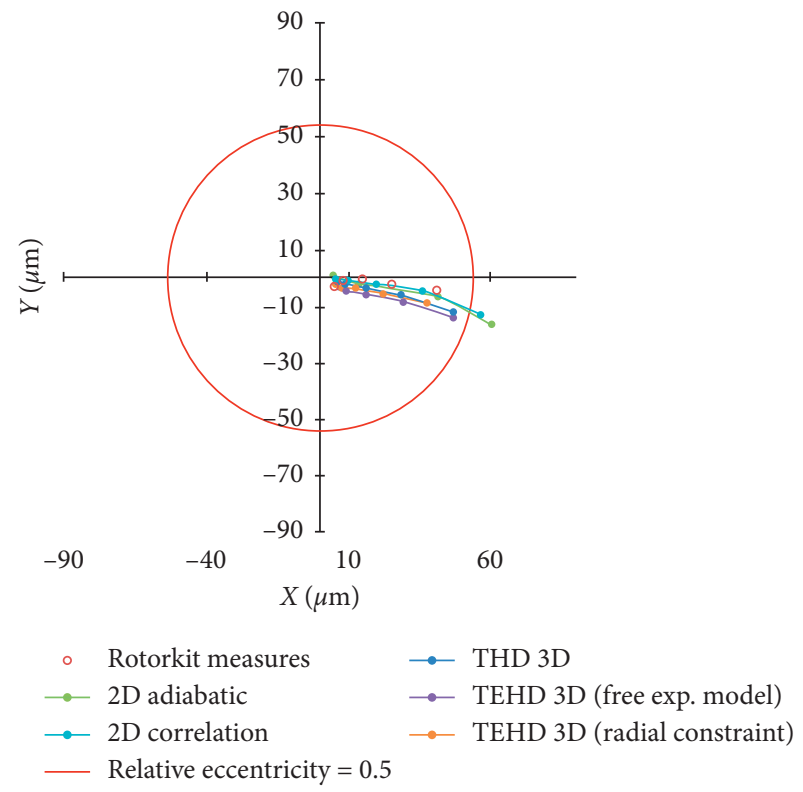

FIGURE 14: Mobility plot for the modified RK with respect to 3D numerical THD and TEHD simulation results in configuration 1.

Differently, the "TEHD 3D" simulation requires the cold clearance value $(0.85 \mathrm{~mm})$ as input so that the thermomechanical deformation is computed during the simulation. 


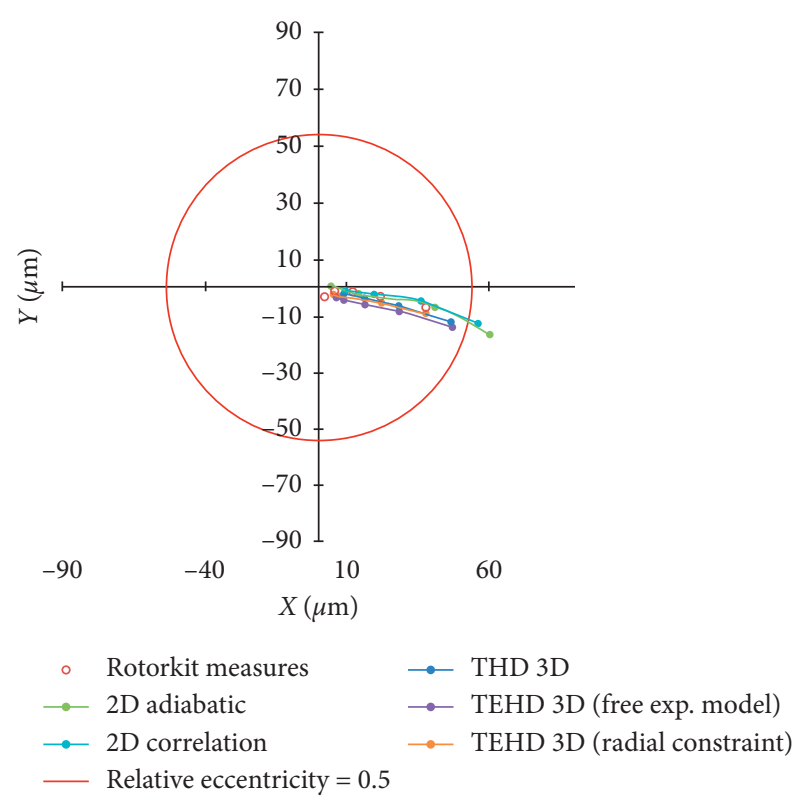

FIGURE 15: Mobility plot for the modified RK with respect to 3D numerical THD and TEHD simulation results in configuration 2.

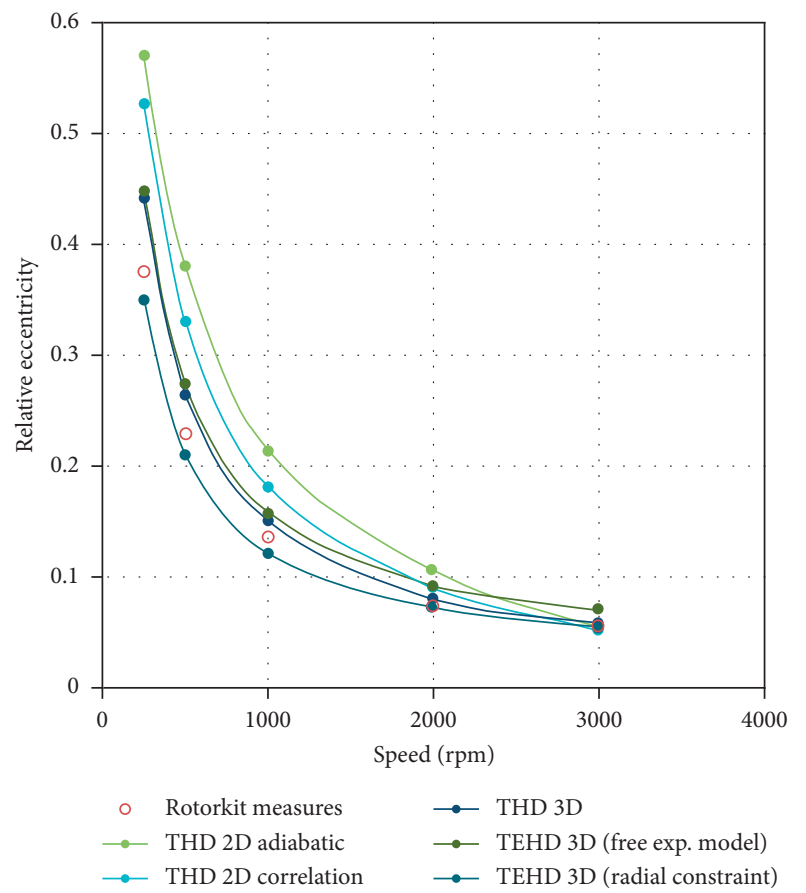

FIGURE 16: Relative eccentricity plot for the modified RK with respect to $3 \mathrm{D}$ numerical THD and TEHD simulation results in configuration 1 .

Therefore, response differences between "THD 3D" and "TEHD 3D" models are only related to the radial thermal deformation distribution and not to its mean value. While thermal deformations cause significant bearing displacements (in the order of $10 \mu \mathrm{m}$ ), the mechanical ones (due to hydrodynamic pressure) yield negligible displacements

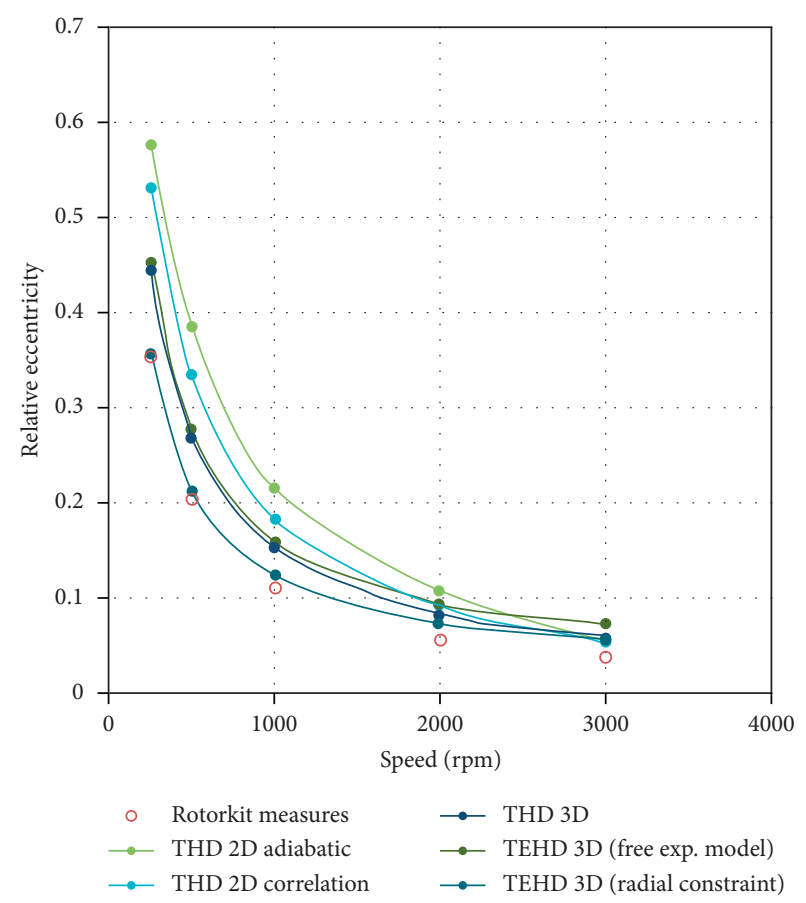

FIgURE 17: Relative eccentricity plot for the modified RK with respect to $3 \mathrm{D}$ numerical THD and TEHD simulation results in configuration 2 .

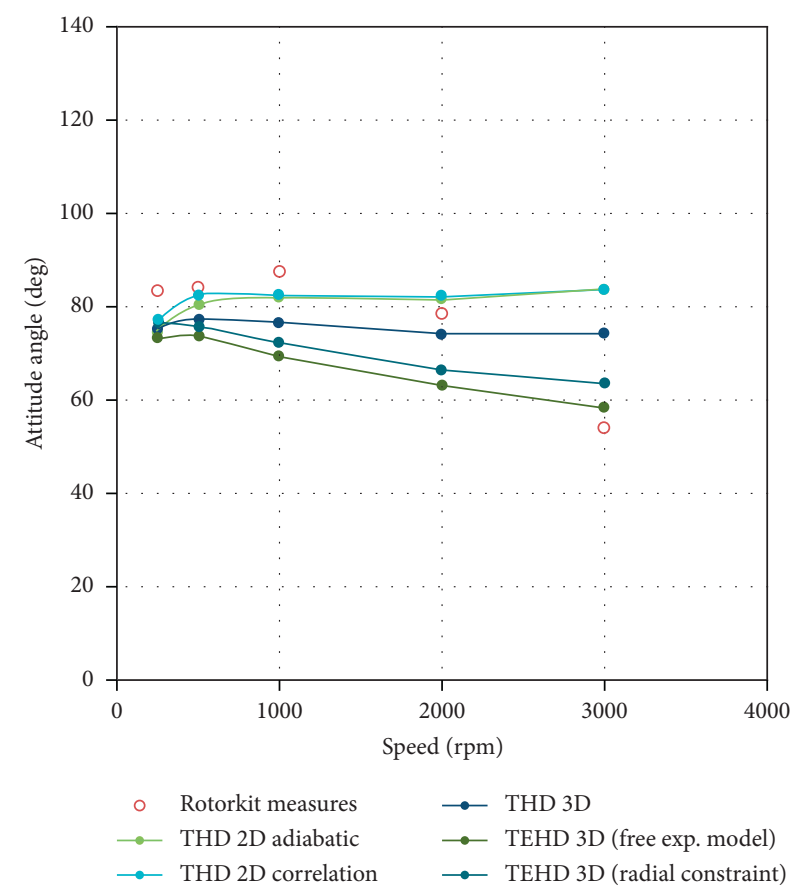

FIgURE 18: Attitude angle plot for the modified RK with respect to 3D numerical THD and TEHD simulation results in configuration 1.

(micron fractions even at higher speeds) in comparison with the minimum film thickness (about $85 \mu \mathrm{m}$ ). Indeed, due to the very low bearing load, the hydrodynamic pressure (in the 


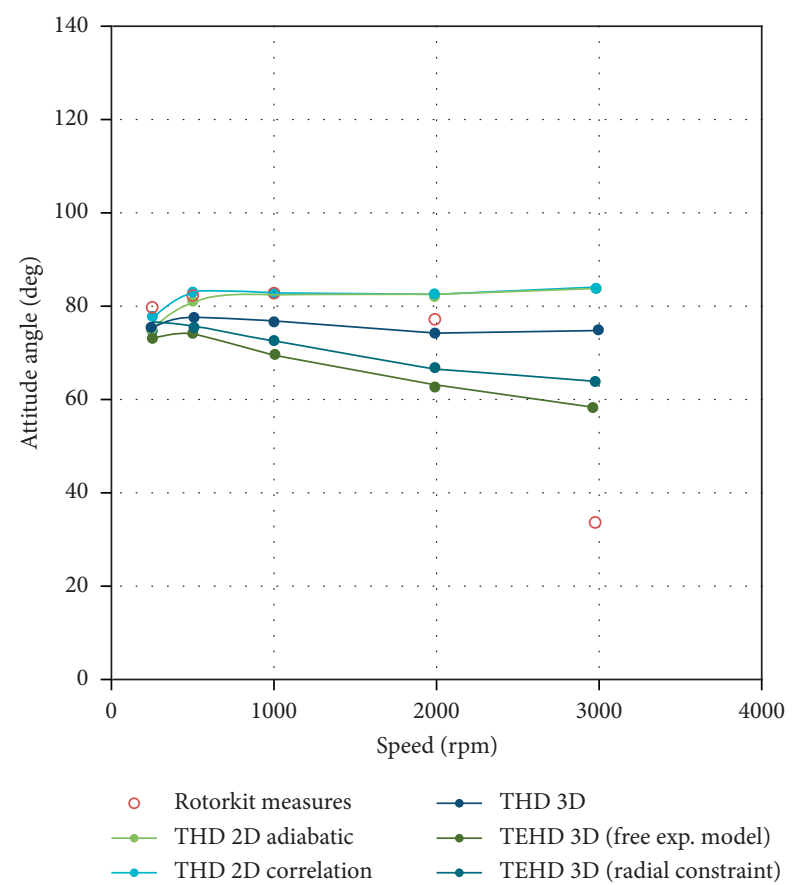

FIGURE 19: Attitude angle plot for the modified RK with respect to $3 \mathrm{D}$ numerical THD and TEHD simulation results in configuration 2.

order of bar fractions) cannot cause important mechanical deformations. The influence of constraint locations in the thermomechanical submodel is also not very significant. The "radial constraint" submodel yields better agreement with experimentation than the "free-expansion" one. The actual structure should be in an intermediate condition between the conditions simulated by the two submodels, since the region included between the two O-rings is somehow constrained but it can also expand. Generally, differences on the journal positions predictions provided by simulation and experimentation are not substantial, particularly in the modified RK configuration.

3D models, by using a quasi-3D mass-energy conserving algorithm, have shown an excellent agreement between numerical and experimental results published in the literature as far as temperatures are concerned [9].

Therefore, their prediction of journal location is also expected to be sufficiently reliable. Actually, differences on the journal positions predictions provided by simulation and experiments are not substantial in the modified RK configuration.

Comparisons of relative eccentricity errors for both $3 \mathrm{D}$ and 2D models are depicted in Figures 20-23 for configurations 1 and 2, respectively. Figure 20 shows that the TEHD simulation almost for all of the speeds can yield errors lower than the "THD 3D" simulation, while between the two TEHD models, the most reliable is the "TEHD 3D radial constraint," as already mentioned.

Figure 21 compares, in terms of relative eccentricity errors, the two TEHD 3D models and the most consistent $2 \mathrm{D}$ simulation for configuration 1 . The " $2 \mathrm{D}$ correlation"

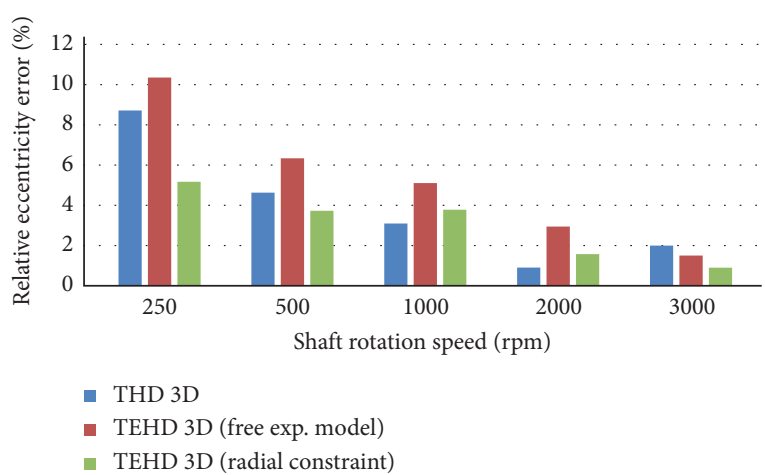

FIgURE 20: Difference between relative eccentricities measured and computed by means of $3 \mathrm{D}$ models for the modified RK in configuration 1 .

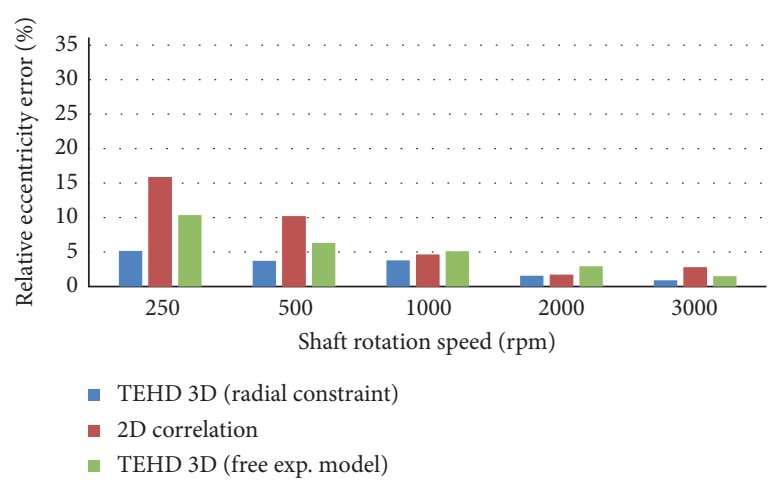

FIGURE 21: Difference between relative eccentricities measured and computed by means of most consistent $3 \mathrm{D}$ and $2 \mathrm{D}$ models for the modified RK in configuration 1.

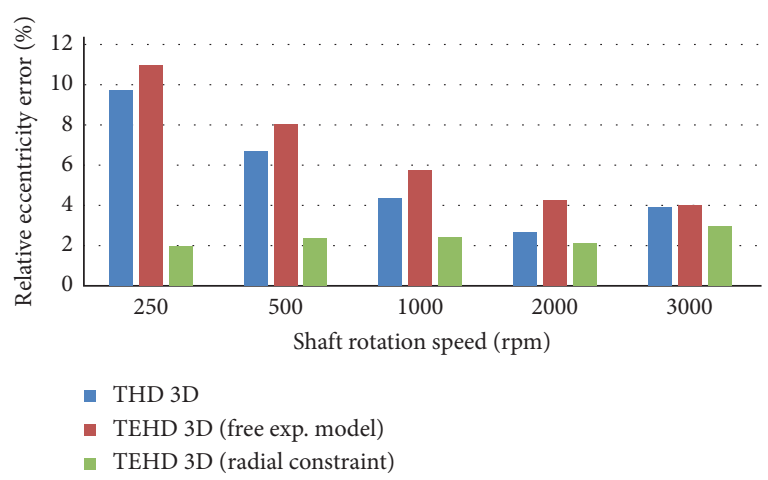

FIGURE 22: Difference between relative eccentricities measured and computed by means of $3 \mathrm{D}$ models for the modified RK in configuration 2 .

model is not far from the results of the two 3D TEHD models for all of the angular speeds.

Figure 22 shows that the improvement in journal location prediction obtained by using the "TEHD 3D radial constraint" model instead of THD simulations, already 


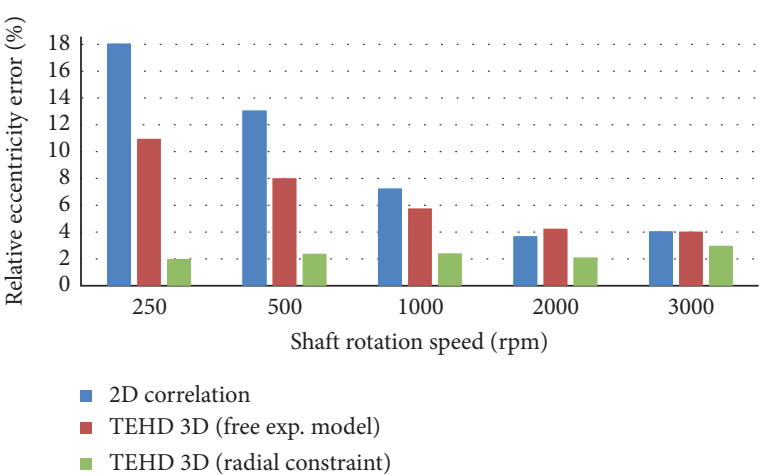

FIGURE 23: Difference between relative eccentricities measured and computed by means of most consistent $3 \mathrm{D}$ and $2 \mathrm{D}$ models for the modified RK in configuration 2.

observed for configuration 1 (Figures 20 and 21), is even more evident for configuration 2 .

Finally, Figure 23 shows for configuration 2 a further improvement in eccentricity prediction of TEHD simulations against $2 \mathrm{D}$ models. Indeed, eccentricity errors of the most consistent 2D THD model ("2D correlation") are always greater and comparable in comparison with errors of "TEHD radial constraint" and "TEHD 3D free expansion" models, respectively.

\section{Conclusions}

The comparison between numerical and experimental results presented in this paper underlines a consistent behaviour of simulation models even with very small clearances, which reliability is enhanced by model complexity and accuracy. Furthermore, a good correlation between journal locations predicted by numerical computations and measured in modified RK has been found out. Therefore, a relative radial clearance of 8/1000 fulfils the thin film Reynolds hypothesis on which calculation models are based. Furthermore, since FEM codes had been already validated in the past, this also confirms that the modified test bench is reliable for further experimental investigations on this type of journal bearings, allowing us to study their dynamic behaviour in a next work.

TEHD analysis results prove that, while displacements due to hydrodynamic pressures are negligible, thermal deformations strongly affect journal position even under low external load (rotor weight is around $0.5 \mathrm{~kg}$ ) and small temperature rise in the bearing. This is due to the high expansion coefficient of the bearing polycarbonate material and the high differential thermal dilatation between steel journal and polymeric bush. After a series of experiments and related data processing, reasonable temperature boundary conditions have been determined on the basis of the temperature control at the bearing supply and simulations performed by means of different models.

Discrepancies found in journal center location predictions may also be ascribable to oil temperature variations with rotation speed. Indeed, bearing supply oil temperature control has shown that such variations are not substantial so that they have not been simulated numerically. This can explain part of the obtained differences between experimental and numerical results.

From the relevant results, the most accurate simulation model for the bearing in analysis has been identified. It includes three-dimensional simulation of heat exchange phenomena. Indeed, at the rotational speeds investigated (250-3000 rpm), the thermal model is crucial in the assessment of bearing static characteristics.

The reduction of relative radial clearance from original to modified RK values has improved the correlation between experiments and real-world applications as well as their agreement with numerical results from in-house developed FEM codes implemented for lubrication analysis. This result is the starting point of future studies about dynamic behaviour of journal bearings and, particularly, about fluid-structure interactions in this class of fluid film bearings. Nevertheless, industrial bearing casings are still different from our test-rig ones in that they are usually manufactured in metallic materials. Therefore, thermomechanical behaviour in real-world bearings differs from our experimental models and numerical simulations, so that temperature and thermal displacement distribution within the bearing pair cannot be fairly compared. Obviously, in the present work, we have assumed as main simulation parameter an average hot clearance and we have subsequently run the bearings in order to achieve that corresponding operating condition. Therefore, our numerical and experimental assessments of journal center location are reasonable and consistent. In order to appropriately deal with industrial bearings considering thermomechanical effects, only the experimental device should be enhanced, simply by manufacturing a metallic bushing. On the contrary, our numerical model would not require any correction. We expect that employing a metal bush would simplify experimental procedure by both improving repeatability and ensuring quicker stationarity of experimental conditions, thus allowing to study even lower relative clearance ratios. We have not yet adopted this expedient as we are gradually updating an existing test rig. Indeed, in order to achieve the clearance adjustments required for the present investigation, only the journal has been modified accordingly. The high differential thermal dilatation between PC and steel makes it practically impossible to study clearance ratios lower than $3 / 1000$ by assuming an average running temperature of $40^{\circ} \mathrm{C}$.

In future research activity, a completely new and original test-rig setup is going to be designed and will be employed for the static and dynamic analysis of hydrodynamic journal bearing-rotor systems with smaller relative clearances, realistic loads, and metallic bushings.

\section{Data Availability}

The data used to support the findings of this study are stored in a dedicated laboratory server and are not shared online.

\section{Conflicts of Interest}

The authors declare that they have no conflicts of interest. 


\section{Acknowledgments}

This project has received funding from the European Union's Horizon 2020 Research and Innovation Programme under grant agreement no. 764706 and Pump-Heat Project (https://www.pumpheat.eu/).

\section{References}

[1] C. A. Niccolini Marmont Du Haut Champ, F. Stefani, and P. Silvestri, "Development of a new test rig for the analysis of hydrodynamic bearings for rotors of microGT," E3S Web of Conferences, vol. 113, p. 03002, 2019.

[2] N. J. Huggins, "Hydrodynamic instability in plain journal bearings," Ph.D. thesis, Imperial College, London, UK, 1961.

[3] K. Sandvik, A. Lehtovaara, E. Makkonen, M. Kallio, K. Kuvaja, and V.-T. Kuokkala, Development of a Test Device for the Evaluation of Journal Bearings, Tampere University of Technology, Tampere, Finland, 2012.

[4] J. Tůma and J. Biloš, "Fluid induced instability of rotor systems with journal bearings," Journal of Engineering Mechanics, vol. 14, no. 1-2, pp. 69-80, 2007.

[5] V. Meruane and R. Pascual, "Identification of nonlinear dynamic coefficients in plain journal bearings," Tribology International, vol. 41, no. 8, pp. 743-754, 2008.

[6] J. Tůma, A. Bilošová, J. Šimek, and R. Svoboda, "A simulation study of the rotor vibration in a journal bearing," Journal of Engineering Mechanics, vol. 15, no. 6, pp. 461-470, 2008.

[7] J. C. Deepak and S. T. Noah, "Experimental verification of subcritical whirl bifurcation of a rotor supported on a fluid film bearing," ASME Journal of Tribology, vol. 120, no. 3, pp. 605-609, 1998.

[8] E. L. B. Van De Vorst, R. H. B. Fey, A. De Kraker, and D. H. Van Campen, "Steady state behavior of rotordynamic systems with," Oil Journal Bearings, ASME Nonlinear and Stochastic Dynamics, vol. 78, pp. 107-114, 1994.

[9] F. Stefani and A. Rebora, "Steadily loaded journal bearings: quasi-3D mass-energy-conserving analysis," Tribology International, vol. 42, no. 3, pp. 448-460, 2009.

[10] F. Stefani, "FEM applied to hydrodynamic bearing design," in New Tribological Ways, pp. 451-476, IntechOpen, London, UK, 2011.

[11] D. E. Bently, J. W. Grant, and P. C. Hanifan, "Active controlled hydrostatic bearings for a new generation of machines," in Proceedings of the ASME Turbo Exposition, Munich, Germany, May 2000.

[12] M. Trachsel, R. Pittiti, and J. Dual, "Friction and 2D position measurements in small journal bearings," Tribology International, vol. 6, 2016.

[13] B. Jacobsson and L. Floberg, The Finite Journal Bearing Considering Vaporization, Transactions of Chalmers University of Technology, Gothenburg, Sweden, 1957.

[14] K. Olsson, Cavitation in Dynamically Loaded Bearings, Transactions of Chalmers University of Technology, Gothenburg, Sweden, 1965.

[15] A. Kumar and J. F. Booker, "A mass and energy conserving finite element lubrication algorithm," Journal of Tribology, vol. 116, no. 4, pp. 667-671, 1994.

[16] C. Gazley, "Heat-transfer characteristics of the rotational axial flow between concentric cylinders," Transactions of the ASME, vol. 80, pp. 79-90, 1958.

[17] F. Stefani, "Design and fast verification of pocket elliptical journal bearings," Industrial Lubrication and Tribology, vol. 66, no. 3, pp. 393-401, 2014.
[18] J. Bouyer and M. Fillon, "An experimental analysis of misalignment effects on hydrodynamic plain journal bearing performances," Journal of Tribology, vol. 124, no. 2, pp. 313-319, 2002. 